\title{
Red weepy ears
}

Cong Sun, Jim Muir

CASE

A Caucasian woman aged 18 years developed a well-defined erythematous vesicular eruption with clear non-purulent exudates on the ear lobules and adjacent inferior neck area (Figure 1). Both of her ears had been pierced two weeks earlier at an accredited piercing salon. This was her first piercing. She had been diligent with her care of the new piercings and had used an antiseptic spray given to her by the salon staff to apply to the area. She was otherwise medically well with no personal or family history of skin disease or atopy, and she was not taking any regular medications.

The patient initially self-treated the rash by switching to another brand of antiseptic spray from a local pharmacy, which only exacerbated the eruption. The patient was then prescribed oral cephalexin $250 \mathrm{mg}$ and mupirocin $2 \%$ ointment for a diagnosis of a suspected wound infection. The patient was also instructed to continue using the antiseptic spray and leave the earrings in. Both antiseptic sprays contained benzalkonium chloride as the main ingredient.

There was no response to antibiotic therapy. Ultimately, the patient stopped using the antiseptic spray because of the stinging sensation when applied.

Cessation of the antiseptic sprays brought significant improvement. The vesiculation and erythema drastically improved only three days after stopping the sprays (Figure 2).
QUESTION 1

What is the most likely diagnosis in this clinical scenario, and what would be considered in the differential diagnosis?

\section{QUESTION 2}

Which ingredient in both brands of antiseptic sprays is likely to be the culprit in this case?

\section{QUESTION 3}

What is contact dermatitis?

\section{QUESTION 4}

What is benzalkonium chloride and with which conditions is it associated?

\section{QUESTION 5}

What is the treatment of contact dermatitis?

\section{ANSWER 1}

The most likely diagnosis in this scenario is a contact dermatitis of allergic or irritant nature due to the antiseptic sprays. This is indicated by the morphology of the eruption, well-defined borders and bilateral occurrence. The area involved also offers an important clue as it fits the pattern of something being sprayed onto the piercing site. The significant improvement that occurred post-withdrawal of the offending antiseptic sprays also supports this diagnosis.

Allergic contact dermatitis due to nickel, cobalt or gold can be part of the differential diagnosis as these are common constituents of jewellery. ${ }^{1}$ Nevertheless, it is unlikely for the eruption to extend down to the neck.
Wound infection as a complication of ear piercings is plausible. ${ }^{1,2}$ However, for it to occur in both ears and extend into this patient's distribution of skin is unlikely. The absence of localised pain or tenderness and fever would be atypical for an infection.

Other dermatoses such as atopic dermatitis and psoriasis can occur in this location. However, the patient's lack of family and personal history of skin disease as well as the absence of involvement elsewhere make these diagnoses unlikely.

ANSWER 2

The most likely offending ingredient is benzalkonium chloride, which is well known to cause irritant and allergic contact dermatitis. ${ }^{3}$

\section{ANSWER 3}

Contact dermatitis is an inflammation of skin induced by an external agent; it can be divided into irritant and allergic dermatitis. ${ }^{4,5}$ Irritant contact dermatitis occurs as a result of an inflammatory reaction triggered by direct damage to the skin caused by exposure to either chemical or physical agents. ${ }^{6,7}$ Allergic contact dermatitis is a delayed type IV hypersensitivity reaction to an agent that has been sensitised previously. ${ }^{5}$ Clinically, contact dermatitis presents with erythema, vesiculation, scaling and bullae formation. ${ }^{6}$ Inflammation only occurs in areas that have been in contact with the causative agent; therefore, the rash is often well confined and has clear demarcations. ${ }^{4}$ Nevertheless, secondary infections and id reactions can produce distal site involvement in contact dermatitis. 
A patch test can be used to diagnose the causative agent; however, it is expensive and time consuming and can lead to sensitisation, which outweighs the benefit in the present case as the rash completely resolved with simple avoidance of the spray.

\section{ANSWER 4}

Benzalkonium chloride is a quaternary ammonium cationic agent widely incorporated into cosmetics, skin disinfectants, ophthalmic preparations and other pharmaceutical products. ${ }^{8}$ It is a significant irritant and can also act as a novel allergen. ${ }^{8,9}$ Reports of irritant eyelid, scalp and flexural dermatitis; stomatitis; cheilitis; hand dermatitis and granular parakeratosis have been reported with products containing benzalkonium chloride. ${ }^{3,7,10}$

\section{ANSWER 5}

Avoidance of the offending agent is paramount in the treatment of contact

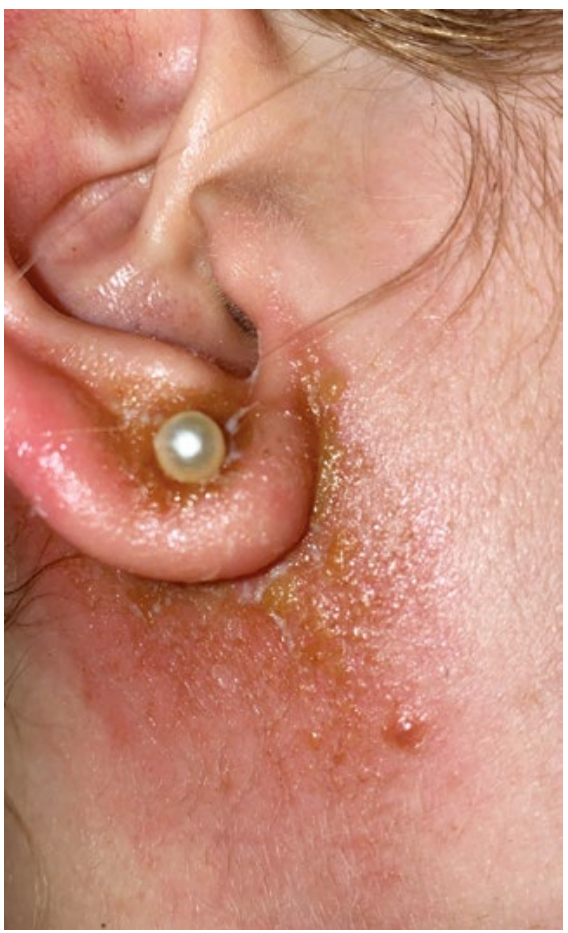

Figure 1. Erythematous vesicular eruption of the right ear lobule and adjacent neck area two weeks after ear piercings; left ear has a similar appearance dermatitis of irritant or allergic aetiology. ${ }^{5}$ Topical corticosteroids are beneficial in the treatment of allergic contact dermatitis, but the evidence for irritant contact dermatitis is less robust. ${ }^{5}$ Methylprednisolone aceponate is known to have lower risk of inducing skin trophy and perioral dermatitis with applications to the head and neck area when compared with fluorinated steroids such as betamethasone dipropionate. ${ }^{11}$ Lipid-rich fragrance-free moisturisers are efficacious in restoring the compromised barrier function in contact dermatitis. ${ }^{5}$

\section{CASE CONTINUED}

The patient was subsequently diagnosed with contact dermatitis. She was prescribed methylprednisolone apocenate fatty ointment and told to avoid further exposure to the antiseptic sprays. Her skin lesions resolved without further occurrence.

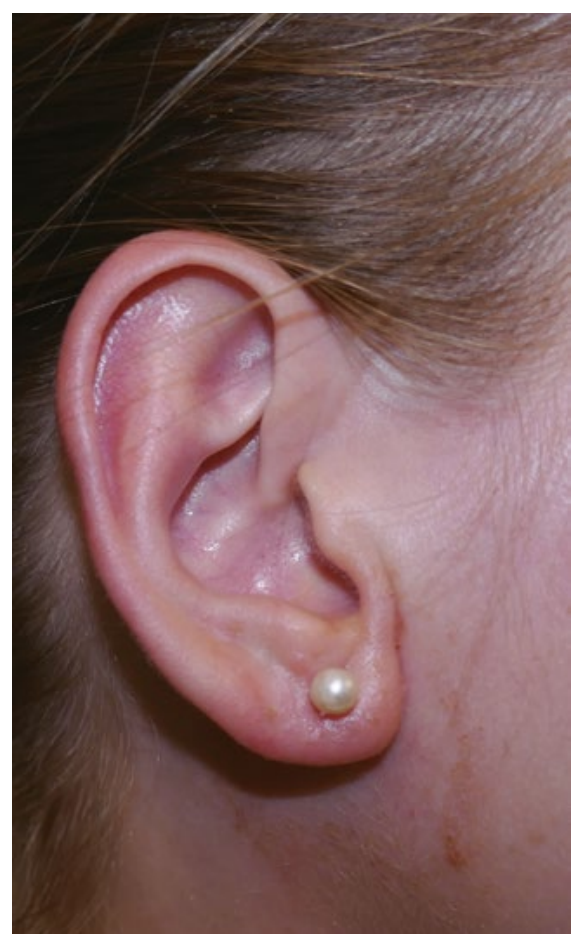

Figure 2. Significant improvement after the patient stopped using antiseptic spray for three days

\section{Authors}

Cong Sun BSc, MD Resident Medical Officer Princess Alexandra Hospital, Qld. tom.cong.sun@gmail.com

Jim Muir MBBS, FACD, Consultant Dermatologist, Mater Misericordiae Hospital, Qld

Competing interests: None.

Funding: None.

Provenance and peer review: Not commissioned, externally peer reviewed.

\section{Acknowledgements}

The authors would like to thank the patient for her permission to use her clinical information for this article.

\section{References}

1. Meltzer DI. Commentary - Complications of body piercing. Pediatr Dermatol 2008;25(2):283-84. doi: 10.1111/j.1525-1470.2008.00659.x.

2. Tweeten SS, Rickman LS. Infectious complications of body piercing. Clin Infect Dis 1998;26(3):735-40. doi: 10.1086/514586.

3. Hann S, Hughes TM, Stone NM. Flexural allergic contact dermatitis to benzalkonium chloride in antiseptic bath oil. Br J Dermatol 2007:157(4):795-98. doi: 10.1111/j.13652133.2007.08134.x

4. Tan $\mathrm{CH}$, Rasool S, Johnston GA. Contact dermatitis: Allergic and irritant. Clin Dermatol 2014;32(1):116-24. doi: 10.1016/j. clindermatol.2013.05.033.

5. Saary J, Qureshi R, Palda V, et al. A systematic review of contact dermatitis treatment and prevention. J Am Acad Dermatol 2005;53(5):845. doi: 10.1016/j.jaad.2005.04.075.

6. English JS. Current concepts of irritant contact dermatitis. Occup Environ Med 2004;61(8):722-26. doi: 10.1136/oem.2003.010710.

7. Oiso N, Fukai K, Ishii M. Irritant contact dermatitis from benzalkonium chloride in shampoo. Contact Dermatitis 2005;52(1):54. doi: 10.1111/j.01051873.2005.0483j.x.

8. Dao H Jr, Fricker C, Nedorost ST.

Sensitization prevalence for benzalkonium chloride and benzethonium chloride. Dermatitis 2012;23(4):162-66. doi: 10.1097/ DER.0b013e318260d78d.

9. Wentworth AB, Yiannias JA, Davis MD, Killian JM Benzalkonium chloride: $A$ known irritant and novel allergen. Dermatitis 2016;27(1):14-20. doi: 10.1097/ DER.0000000000000160.

10. Robinson AJ, Foster RS, Halbert AR, King E, Orchard D. Granular parakeratosis induced by benzalkonium chloride exposure from laundry rinse aids. Australas J Dermatol 2017;58(3):e138-e40. doi: 10.1111/ajd.12551.

11. Ruzicka T. Methylprednisolone aceponate in eczema and other inflammatory skin disorders - A clinical update. Int J Clin Pract 2006:60(1):85-92. doi: 10.1111/j.1368 5031.2005.00754.x 